\title{
Growing Insights and Youth Knowledge in the NFT Hydraulic Application (Nutrient Film Technique)
}

\author{
Author \\ Johan Andri Pratama, Alfian Hamdani, Aryanda Tata Permana, Nanang Khoirul Umam, Andi Rahmad Rahim
}

\section{Correspondence}

Universitas Muhammadiyah Gresik

\begin{abstract}
The more rapid growth of technology allows humans to work effectively and efficiently. Technology proves the way humans change patterns of significant social change, from those that initially used human power to machines. The way humans use machines is inseparable from the ways and techniques of its use which are effective and efficient. One of the technologies used is the technology of crop cultivation without using soil as a planting medium. The technology introduced is hydroponics. Hydroponics as a way of farming is an approach that has several advantages, namely the use of agricultural land that is not extensive, and the system is not too complicated. The introduction of this technology aims to provide insight and knowledge to the public about the technology of crop cultivation in addition to conventional farming systems. This activity was carried out in Rayung gumuk Village, Glagah District, Lamongan Regency. The hydroponic system that we introduce is the NFT hydroponic system (Nutrient Film Technique). The goal is because the hydroponic system is easily applied and has several significant advantages. The first method of implementation is socialization. This is done to find out the extent to which people's insights and knowledge about hydroponics and the interests and interests of the community towards hydroponic using the NFT system. Moreover, the second is training. It aims to provide techniques and methods for assembling NFT hydroponic installations. From the results of our activities, the community's response to hydroponics is still minimal because some of them still consider hydroponic use too costly and their disinterest in agriculture.
\end{abstract}

Keywords: hydroponics, agricultural technology, NFT

\section{Introduction}

Hydroponics has been used for thousands of years. The Hanging Gardens of Babylon are mostly believed to have functioned the principles of hydroponics. The park was built around $600 \mathrm{BC}$ in Babylon or Mesopotamia. During the X and XI centuries, the Aztecs developed a light gardening system based on hydroponics. They started by building rafts of reeds and roots. On the raft, it is filled with a little soil from the bottom of the lake and then floats out into the water. Plants will grow on the raft, roots reach water through the raft and descend into the bottom of the water to look for more nutrients and oxygen.

In 1620, Sir Francis Bacon, a British scientist, carried out research on small land and infertile land, which triggered an extraordinary wave of hydroponic research. This research continued until the nineteenth century with the publication of a book on "Water Culture Methods for Plants Growing without Soil." In its use in commercial agriculture, it was first introduced by Berkeley
Received: 13 October 2018. Accepted: 10 December 2018

scientist William Gericke using the " Aquaculture " process. This research is proven by the success of the tomato plants that he created in his house through water and nutritional solutions. After the term cultivation was introduced, he coined the term "Hydroponics."

Hydroponics is plant cultivation by utilizing water without using soil by emphasizing the fulfillment of nutritional needs for plants. Water needs in hydroponics are less than water requirements in cultivation with soil. Hydroponics uses adequate water, so it is suitable to be applied in areas that have a limited water supply. Instead, hydroponics uses other media and special nutritional water so that plants can grow well like plants planted on the ground. Western agricultural experts say, that the hydroponic farming system is " Low of Return ", which means a system that seeks to return all types of hydroponic material into the soil, both in the form of residues and plant and livestock wastes which then aim to feed plants, the philosophy that underlies hydroponic 
agriculture is to develop the principles of feeding the soil, which then provides the food for plants ( Feeding The Soil That Feeds The Plants ), and not giving food directly to plants.

NFT (Nutrient Film Technique) is one of the types in hydroponics which was first developed by Dr. A. J. Cooper at the Glasshouse Crops Research Institute, Littlehampton, England in the late 1960s and developed in the early 1970s commercially. The basic concept of NFT is a method of cultivating plants with plant roots growing on a shallow and circulating nutrient layer so that plants can get enough water, nutrients, and oxygen. The plant grows in a polyethylene layer with plant roots submerged in water containing nutrient solutions which are circulated continuously with the pump. Area roots in nutrient solutions can develop and grow in partial nutrient solutions so that the top of the plant roots is on the surface between nutrient solution and Styrofoam. The existence of a part of the root in this air allows oxygen to be still fulfilled and enough for healthy growth. Whereas according to (Lingga, 2011) NFT is a hydroponic cultivation model by placing plant roots in shallow water layers. The water is circulated and contains nutrients according to plant needs. Rooting can develop in nutrient solutions. Because around the roots, there is a layer of nutrient solution, the system is known as the Nutrient Film Technique (NFT).

Rayunggumuk Village is a village located in the northern part of Lamongan City and sheltered by Glagah District. Geographically Rayunggumuk village dominated by agricultural fields, both fields, and ponds. The local communities around the majority of their livelihoods are farmers. The agricultural area in Rayunggumuk Village still uses conventional farming techniques, in the irrigation system of the rice fields and the surrounding community, it relies on the flow or source of water from the Bengawan Solo river. As the primary source of livelihood for the surrounding community, agricultural land here is used as a dual function. Where when the lean season (dry) agricultural land used as rice fields planted with rice, the rice crop harvest season each year has one to two times. Also, during the rainy season agricultural land is used as fish ponds, and for farms, the harvest season is two to three times the harvest. Therefore, the agricultural sector in
Rayunggumuk village became the central capital in the development as well as improving the economy of the village community.

As the primary source as well as the economic strength of the village, the agricultural sector here is still managed in conventional ways, for example during the rice harvest season; the village community still relies on human labor to manage it. Moreover, even more concerning is the lack of role of village youth in the utilization and management of the village agricultural sector.

Youth as the next generation of villages ignore this; they focus more on activities that are practical and flexible. They realize that agriculture is a field that is too complex and exhausting. The interest and interest of the village youth in the agricultural sector was minimal, some of them preferred to leave the village to work in urban areas and have education outside the village even though they are the source or assets of the villagers to continue and improve the standard of life of the village that is empowered and advancing.

We realize that agriculture is not only able to be applied in a large plot of land with time-consuming and labor-intensive work activities. Although agriculture essentially includes farming methods, in the context of agriculture it has also expanded into the field of technology. One of them is hydroponics. Hydroponics as modern agricultural technology introduces and offers agricultural concepts that are effective and efficient. In its use, hydroponics provides an opportunity and opportunity for the community to feel and use it as an effective and efficient way of farming.

\section{Targets}

1. Having environmental awareness and being able to utilize the environment of his village

2. Have insight and knowledge about hydroponics

3. Can implement and assemble NFT hydroponic installations

\section{Output}

1. The community has insight and knowledge of hydroponic agricultural technology

2. The community can apply the NFT hydroponic system

3. The community can make or produce the NFT hydroponic system 


\section{AIM}

1. The establishment of environmental awareness and being able to utilize the environment of his village

2. The formation of insight and knowledge about hydroponics

3. The ability to implement and assemble NFT hydroponic installations

\section{Method}

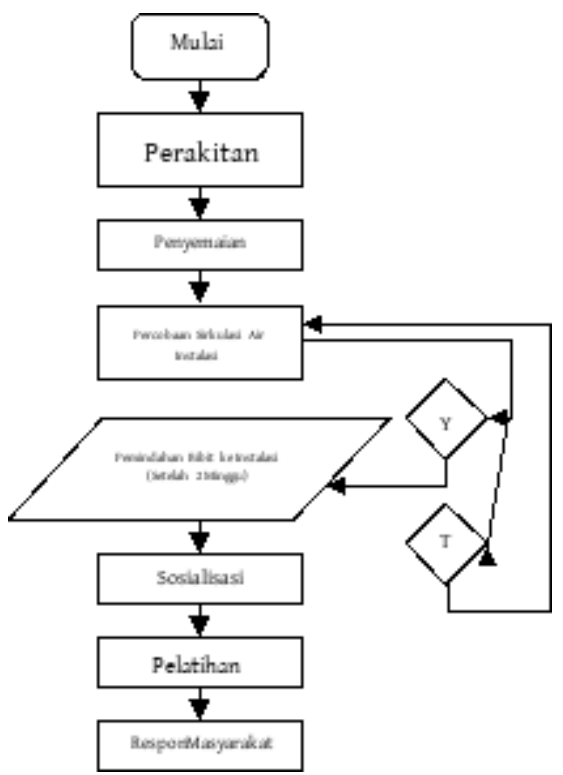

Picture 1. Activity Flow Chart

\section{Priority Problems}

Rayunggumuk village is a village whose area/environment is dominated by agricultural land, namely rice. As a rice-producing village, this village is a village surrounded by soft/muddy soil structures, which influences the way of farming the village community. Furthermore, utilizing water sources in the village which is the flow of water sources directly from the river so that in the process of farming it is also possible not to be short of water. However, the water content in Rayunggumuk Village is still brackish so that when used for farming it must pay attention to what plants or vegetables will be planted. Moreover, in the aspect of HR, especially in the target activities that are specifically for youth, they should be the successor relay of the village's sustainability proven to be minimal in their interest and interest in managing the village agricultural sector. They (youth) prefer to work in the industrial sector rather than taking care of agriculture. This is the reason why hydroponics as an agricultural technology seen regarding its use is very suitable to be managed by those who are still young. Because the use and management are different significantly from conventional agriculture.

From here we have the initiative to use hydroponics as an added value for the village community because, in addition to natural and practical ways, hydroponics also does not use land as a planting medium, small land use, and minimal use of water. Therefore, as agricultural technology, hydroponics is also capable of creating jobs and also making village forces self-sufficient. We are aware of that as well to open our minds to the public about the importance of using the land for productive things. Also, at this time, the eviction of agricultural land is used for housing, real estate, infrastructure, industrial areas, and large buildings. Because of that, the community is also given insight into the importance of utilizing the environment and managing village resources to be an added value to the community.

\section{Problem Solving Approach}

This program is carried out in the form of socialization and training. In the form of socialization, the community is introduced to the understanding of the benefits of hydroponics for the surrounding environment, and this aims to provide insight and knowledge to the community that besides conventional agriculture there is also a more effective and practical agricultural technology. While in the implementation of the training, the community was technically introduced to how to make hydroponics. In this case, the community was introduced gradually from seeding to harvesting. The target of our program participants is youth of the villagers. This is aimed at initiating young people regarding the benefits of hydroponics besides that youth in the village is an active society that consistently contributes their thoughts to hamlets and villages. The hydroponic system that we introduce is the NFT hydroponic system (Nutrient Film Technique). In its application, this system is relatively easy and practical because, in addition to its easy assembly, its use does not use much water and considerable land. Despite its easy use, this system also uses a large amount of capital because in the installation it takes quite a lot of material. 


\section{Plan of Activities}

\section{- Materials and Tools Needed}

1. Pipe

2. Pipe Connector

3. Wood

4. Nail

5. Drill

6. Net-pot

7. Rockwool

8. Seeds

9. Water

10. Nutrient Solution

11. Bucket

12. Water pump

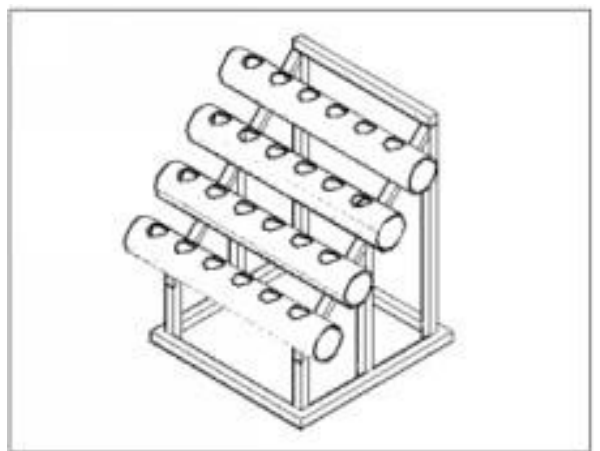

Figure 2. NFT Hydroponic Prototype

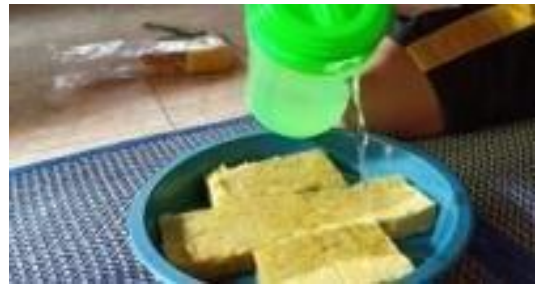

Figure 3. Seeding is carried out from August 7-21, 2018

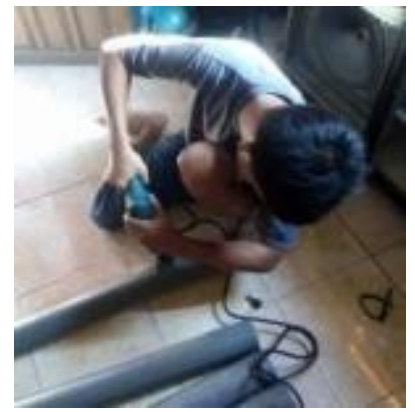

Figure 4. Assembling hydroponic installations is carried out from 12 - 19 August 2018

\section{Place of execution}

1. Preparations ranging from seedling to assembling hydroponic installations are carried out at the KKN location
2. The socialization and training program were held in the Rayunggumuk Village Hall

\section{Partner Participation in Activities}

The partners of hydroponic socialization and training activities are the village community, especially the Karang Taruna Village, Rayunggumuk Village. Karang Taruna of the village of Rayunggumuk consists of 4 youth associations.

\section{Types of Outputs According to Activities}

1. NFT hydroponic installation products

2. Insights and knowledge to the public about NFT hydroponic agricultural technology (Nutrient Film Technique)

\section{Results and Discussion}

Every stage of the work program implementation process technically more or less run smoothly. Because in its implementation there are no obstacles, both from financial factors, human resources, and the material presented. However, some things are still lacking in the implementation process, one of which is our competence in mastering the work program.

Besides that, the community's interest in hydroponics is still said to be minimal even though it is seen from the community background and geographical location of villages in agricultural areas. However, concerning the people present, some of them were enthusiastic about hydroponics. Hydroponics as an agricultural technology offers a practical approach to engineering and manufacturing. In the context of sustainable agriculture, hydroponics also requires substantial capital both concerning finance and knowledge. Whereas for human resources needed, hydroponic cultivation emphasizes the ability and competence of human resources because, in the context of cultivation, hydroponics must pay attention to all aspects thataffect the agricultural sector. Therefore, in its implementation, we only emphasize the scale of hobbies. Because besides knowing the attention and interest of the community, we also want to see to what extent our insight, knowledge, and experience of hydroponics can be continued in the scale of cultivation. From here we provide a benchmark in the implementation of work programs on hydroponics. 
In its implementation, hydroponic socialization and training give an impression to the public that this farming system is still at an implicit level. They have a minimal understanding of the use of hydroponics as an effective farming system, and some of them still assume that hydroponics is a new agricultural system. Their attention and interest in agriculture still lack so that in the process of implementation, some of them seem to pay less attention. We also realize that in the presentation of material and our competencies in mastering the material we still cannot say the maximum, because of our lack of insight, knowledge, and experience in hydroponics.

\section{Conclusions}

Seeing the public response to the activities carried out is that they still have no interest and interest in hydroponic agricultural technology. This was due to their lack of interest in agriculture and their disinterest in farming activities. Although substantially the activities that have been carried out encourage enthusiastic one of the participants to add insight and benefits of knowledge about hydroponics to them. This can be seen from the activities of those who often ask about hydroponics. So, what has been done in this activity is the result of the NFT hydroponic installation product for the Rayunggumuk Village community.

\section{Suggestions}

We realize that in the implementation of work programs there are still many shortcomings, especially the lack of insight, knowledge, and experience. Besides, the competencies of each are still in the learning process.

\section{Reference}

Suryani, Reno.2015 Hydroponics, Cultivation of Plants without Soil, Clean and Easy.Yogyakarta: ARCITRA.

clinichydroponics.com/basic-systems-hydroponicsand-how-system-hydroponics-that-work-part6-nutrient-film-technique-nft/

Wibowo S, Asriyanti A.2013 Hydroponic NFT application on Pakcoy Cultivation (Brassica rapa chinensis). In the Journal of Applied Agricultural Research Vol.13 (3): 159-167. Banjarnegara Polytechnic 